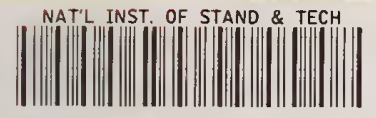

Al1105 974181

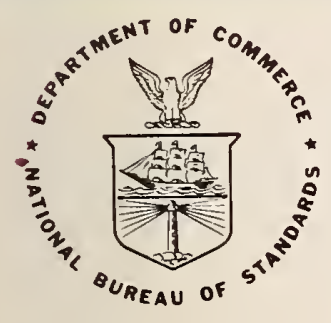

NBS TECHNICAL NOTE 1181

U.S. DEPARTMENT OF COMMERCE/National Bureau of Standards

\title{
A High-Speed \\ Data Acquisition System for Fluid Mechanics Measurements
}




\section{NATIONAL BUREAU OF STANDARDS}

The National Bureau of Standards' was established by an act of Congress on March 3, 1901. The Bureau's overall goal is to strengthen and advance the Nation's science and technology and facilitate their effective application for public benefit. To this end, the Bureau conducts research and provides: (1) a basis for the Nation's physical measurement system, (2) scientific and technological services for industry and government, (3) a technical basis for equity in trade, and (4) technical services to promote public safety. The Bureau's technical work is performed by the National Measurement Laboratory, the National Engineering Laboratory, and the Institute for Computer Sciences and Technology.

THE NATIONAL MEASUREMENT LABORATORY provides the national system of physical and chemical and materials measurement; coordinates the system with measurement systems of other nations and furnishes essential services leading to accurate and uniform physical and chemical measurement throughout the Nation's scientific community, industry, and commerce; conducts materials research leading to improved methods of measurement, standards, and data on the properties of materials needed by industry, commerce, educational institutions, and Government; provides advisory and research services to other Government agencies; develops, produces, and distributes Standard Reference Materials; and provides calibration services. The Laboratory consists of the following centers:

Absolute Physical Quantities ${ }^{2}$ - Radiation Research - Chemical Physics Analytical Chemistry - Materials Science

THE NATIONAL ENGINEERING LABORATORY provides technology and technical services to the public and private sectors to address national needs and to solve national problems; conducts research in engineering and applied science in support of these efforts; builds and maintains competence in the necessary disciplines required to carry out this research and technical service; develops engineering data and measurement capabilities; provides engineering measurement traceability services; develops test methods and proposes engineering standards and code changes; develops and proposes new engineering practices; and develops and improves mechanisms to transfer results of its research to the ultimate user. The Laboratory consists of the following centers:

Applied Mathematics - Electronics and Electrical Engineering ${ }^{2}$ - Manufacturing Engineering - Building Technology - Fire Research - Chemical Engineering ${ }^{2}$

THE INSTITUTE FOR COMPUTER SCIENCES AND TECHNOLOGY conducts research and provides scientific and technical services to aid Federal agencies in the selection, acquisition, application, and use of computer technology to improve effectiveness and economy in Government operations in accordance with Public Law 89-306 (40 U.S.C. 759), relevant Executive Orders, and other directives; carries out this mission by managing the Federal Information Processing Standards Program, developing Federal ADP standards guidelines, and managing Federal participation in ADP voluntary standardization activities; provides scientific and technological advisory services and assistance to Federal agencies; and provides the technical foundation for computer-related policies of the Federal Government. The Institute consists of the following centers:

Programming Science and Technology - Computer Systems Engineering.

'Headquarters and Laboratories at Gaithersburg, MD, unless otherwise noted; mailing address Washington, DC 20234.

${ }^{2}$ Some divisions within the center are located at Boulder, CO 80303. 


\section{A High-Speed Data Acquisition System for Fluid Mechanics Measurements}

L. P. Purtell

National Engineering Laboratory

National Bureau of Standards

Washington, DC 20234

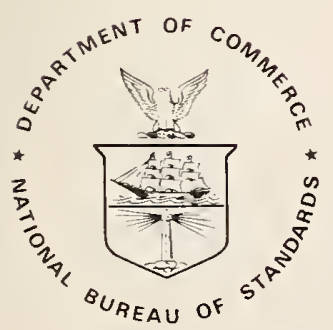

U.S. DEPARTMENT OF COMMERCE, Malcolm Baldrige, Secretary NATIONAL BUREAU OF STANDARDS, Ernest Ambler, Director

Issued November 1983 
National Bureau of Standards Technical Note 1181

Natl. Bur. Stand. (U.S.), Tech. Note 1181, 31 pages (Nov. 1983) CODEN: NBTNAE

For sale by the Superintendent of Documents, U.S. Government Printing Office, Washington, DC 20402 Price

(Add 25 percent for other than U.S. mailing) 


\section{TABLE OF CONTENTS}

Page

I. Introduction 2

II. General Description of System 4

A. Performance Requirements 4

B. Selected System 6

III. A/D Subsystem 8

$\begin{array}{ll}\text { IV. Minicomputer System } & 11\end{array}$

$\begin{array}{ll}\text { V. Velocity and Temperature Measurement Subsystems } & 13\end{array}$

A. Velocity Instrumentation 13

B. Temperature Instrumentation 17

$\begin{array}{ll}\text { VI. System Operation and Performance } & 19\end{array}$

$\begin{array}{ll}\text { A. Velocity Calibration } & 19\end{array}$

$\begin{array}{ll}\text { B. Temperature Calibration } & 19\end{array}$

C. Data Acquisition 21

VII. Further Applications 25

VIII. References 26 



\title{
A HIGH-SPEED DATA ACQUISITION SYSTEM FOR FLUID \\ MECHANICS MEASUREMENTS
}

\author{
L. P. Purte11 \\ Chemical Process Metrology Division \\ Center for Chemical Engineering \\ National Engineering Laboratory \\ National Bureau of Standards \\ Washington, D. C. 20234
}

\section{Abstract}

The requirements, characteristics, and performance of a minicomputerbased data acquisition and analysis system suitable for research in fluid mechanics processes are presented. The particularly stringent requirements imposed by unsteady and turbulent flows are discussed including estimates of the required data acquisition rates and durations.

Key words: data acquisition; fluid mechanics; hot-wire anemometry; measurement; minicomputers; turbulence. 


\section{Introduction}

Transient and unsteady phenomena in fluid mechanics have long been recognized as important to a wide range of fluid flow processes ranging from atmospheric flow, where the time scale may be hours or longer, to shock and detonation waves measured in microseconds. ${ }^{1,2}$ Turbulent flow, inherently unsteady, is involved in a large fraction of these flow processes and has been the subject of much investigation and analysis, though in important ways it remains essentially unconquered. 3

The first approach to turbulent flow that met with some success involved forming long-time averages of pertinent fluctuating quantities, i.e., Reynolds averaging. ${ }^{4}$ Indeed, important descriptive measures of turbulence have resulted from this approach. The necessary measurements required appropriate averaging techniques, and the time-dependence of the flow was eliminated, with an attendant loss of detailed structural information. Likewise, spectral descriptions of turbulence required averages, but here the averages were in phase space. These approaches were based on the viewpoint that turbulent flows were inherently stochastic in nature. However, resulting theoretical and experimental difficulties ${ }^{5}$ have led to a re-examination of this view. A number of experiments, most involving some form of visualization, ${ }^{6}$ have led to the new viewpoint that spacial and short-time temporal correlations ("ordered motion") are of great importance to understanding and predicting turbulent flow phenomena. Ignoring ordered motions in mixing and reacting flows has been found to result in errors as large as $100 \%$ in prediction of concentration values. ${ }^{7}$ Two important consequences for experimentalists are that the time dependence can no longer be ignored, and that spacially resolved measurements are required. 
To measure the properties of these ordered motions requires a twostage operation: detection and then acquisition. This operation is generally referred to as "conditional sampling," i.e., sampling the data stream only when certain conditions have been met. An example is the widely used VITA technique ${ }^{8}$ (Variable Interval Time Averaging) wherein the data is sampled whenever the variance of a selected signal within a time window exceeds some factor times the long-time variance of the signal. Such an occurrence is called an "event." The sampled space-time signals may then be averaged over a number of events to determine average properties. Other types of conditional sampling have been employed from the very simple (sampling when a time derivative exceeds a particular level ${ }^{9}$ ) to the complex (pattern recognition techniques ${ }^{10}$ and matched filter applications ${ }^{11}$ ). Such techniques may be applied not only to velocity signals but also to temperature, composition (concentration), and any other property which can be measured with the necessary space and time resolution.

The computer had been employed successfully even for the timeaveraged measurements required by the earlier approaches to turbulent flow, especially for the more complicated correlations and statistical variables. ${ }^{12}$ However, now their use has become almost mandatory to perform the highly complex functions of educing the ordered motions from time varying measurements of many simultaneous signals. In some instances the signals are recorded in real time, then digitized and analyzed later on a main frame computer. However, the increasing sophistication of minicomputers has led to widespread on-site collection and analysis of data.

The Chemical Process Metrology Division of NBS has assembled and developed such a minicomputer-based data acquisition and analysis system 
suitable for research in a wide variety of fluid mechanics processes. The salient features of this system, including the initial subsystems for velocity and temperature measurement, are described herein, and the performance of the system, as applicable to fluid mechanics measurements, is summarized.

\section{General Description of System}

A. Performance Requirements

Turbulent fluid flows beyond 211 but the earliest stages of their development consist of an extremely broad range of scales of motion. Though the large scale ordered motions are of great importance in contemporary research, the smaller scales cannot be ignored since they are essential to the processes of mixing and diffusion of mass, momentum, energy, and chemical species. A data acquisition system must therefore be capable of resolving all these scales to have broad applicability to the measurement of a wide range of physical processes.

For an estimate of data acquisition requirements for typical large scale motions, the co-flowing circular jet apparatus presently located in the Low Velocity Airflow Facility ${ }^{13}$ may be considered. The large scale motions in the jet at a freestream speed of $3.0 \mathrm{~m} / \mathrm{s}$ for a $50 \mathrm{~mm}$ diameter jet have a time scale on the order of $16 \mathrm{~ms}$. If some sampled property varies by $10 \%$, a $95 \%$ confidence interval of $2 \%$ requires approximately 300 samples, implying a data acquisition duration of around five seconds.

To determine the smallest scales of interest, Kolmogorov's microscales may be estimated for the jet. The Kolmogorov time scale, $\tau$, is given by $\tau=(\nu / \varepsilon)^{1 / 2}$ where $\nu$ is the kinematic viscosity and $\varepsilon$ is the energy 
dissipation rate per unit mass. An inviscid estimate ${ }^{4}$ for $\varepsilon$ assumes that the rate at which large-scale motions supply energy to the smaller scales is proportional to $u / \ell$ where $u$ is the characteristic turbulence velocity and $\ell$ is the integral or outer scale of the turbulence. Thus $\varepsilon \sim u^{3} / \ell$ and $\tau \sim\left(v \ell / u^{3}\right)^{1 / 2}$. Taking $u$ to be $1 \%$ of the jet speed (a typical value) $\ell$ to be $50 \mathrm{~mm}$, and $v$ to be $1.5 \times 10^{-5} \mathrm{~m}^{2} / \mathrm{s}$ leads to $\tau \sim 0.15 \mathrm{~ms}$ and $1 / \tau=6.7 \mathrm{kHz}$. This estimate of the smallest scales may thus be used to set an upper limit on the analog-to-digital conversion rate. It should be noted, though, that the Kolmogorov microscales are much smaller than other definable microscales, such as the Taylor microscale, and may frequently be smaller than necessary for a particular investigation. It serves here simply as a conservative estimate of the small scales.

The increasing sophistication and speed of available minicomputer systems led to a decision early in the system design stage to incorporate a11 of the functions necessary to both acquire and process the desired fluid mechanics data. Data acquisition systems smaller, slower, and having less general capability than full minicomputer systems were available, but it became apparent that only the minicomputer systems had both the speed and storage capacity required.

The maximum $A / D$ conversion rate available on a subsystem meeting the requirements of our system was found to be $250,000 /$ second. From the above analysis it was also estimated that a frequency response of $7 \mathrm{kHz}$ per channel would be adequate. Using the Nyquist criterion that the digitizing rate should be at least twice the highest frequency contained in the signal, sixteen channels of data could be accommodated by the subsystem. The available digital resolution of such a subsystem was 12 bits. Such a resolution was judged satisfactory provided the input signal was reasonably matched to the full scale range of the A/D converter. 
For purposes of calibration it was necessary to have a D.C. coupled system including provision for biasing the D.C. level at some point in order to improve the dynamic resolution. Since all of the initial signals of interest would be biased 0.5 to 1.5 volts D.C., a requirement to handle this range was imposed on the system.

By far the most stringent requirement for the system was that it should acquire the data continuously without any data losses for at least 5 seconds at the highest rate (nominally $250 \mathrm{kHz}$ ). Direct memory access (DMA) techniques are widely used on mini- and micro-computer based systems allowing even substantially higher data rates, but the continuous storage requirement could readily be met only by minicomputer systems using high speed disc storage. This, together with the desirability of performing the detailed, sophisticated data analysis on the same system that acquired the data led to the choice of at least a minicomputer-sized system.

The data analysis functions required that the system have extensive capabilities for higher language programming and sufficient support utilities. Computational speed when manipulating large arrays of data was also desirable considering the required data reduction operations. Since a fairly substantial investment was thus envisioned, future expandability and system support by the supplier became added requirements.

\section{B. Selected System}

A complete, integrated system meeting all of the rather specialized requirements outlined in section II.A was not available; thus, subsystems were specified consisting of the $A / D$ converter, the minicomputer, the anti-aliasing electronic filters, and the fluid mechanics instrumentation. The final system integration was then performed in-house (Figure 1). 


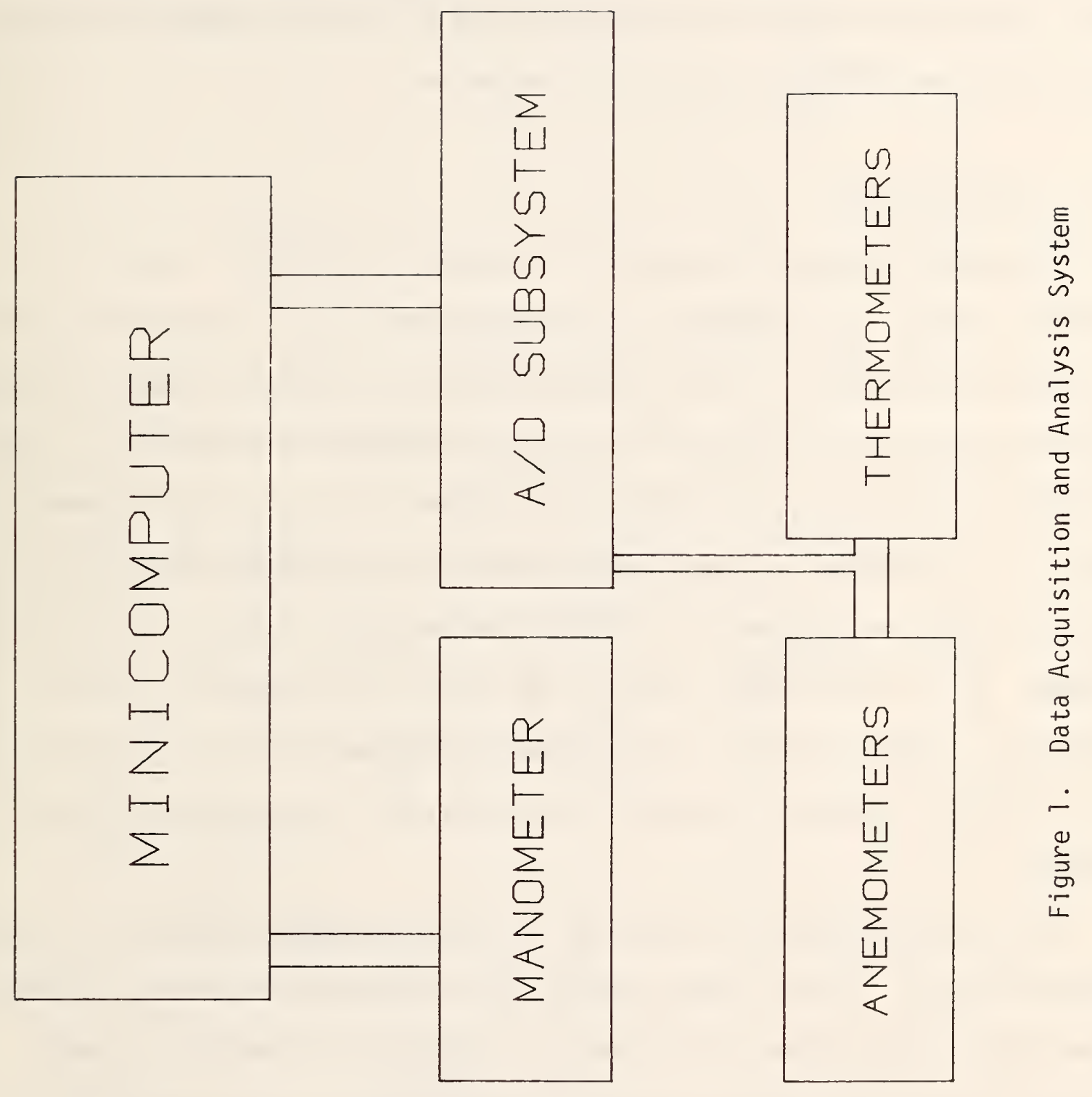


The system thus consists of an A/D converter subsystem including sixteen channels of simultaneous sample-and-hold, a minicomputer system with high-throughput capability, a programmable electronic filter subsystem with sixteen channels, a hot-wire anemometer subsystem, and a resistance-wire temperature subsystem built in-house. The entire integrated system has been successfully tested at a throughput rate of 250,000 samples per second, the maximum rate attainable by the $A / D$ converter.

\section{A/D Subsystem}

The analog to digital converter is a modular system with capacity for multiple channels of simultaneous sample-and-hold and D/A converters as well as analog multiplexors. It has a highly flexible interfacing capability which allows operation by available I/O cards with a minimum of modification. The resulting configuration, including modifications and $I / 0$ cards, is shown in Figure 2. Cycle time for the A/D subsystern, the time between receipt of a convert command and issuance of a conversion-completed strobe, is four microseconds. This is the factor limiting the speed of the system to 250,000 samples per second. However, the computer throughput-to-disc is specified at only 280,000 words per second, so the subsystems are actually very we11matched.

The A/D subsystem may be operated in either a random address or a sequential conversion mode. In the latter mode the analog multiplexor selects channels sequentially until either a specified (by switch) "Tast channel" or the physical last channel in the system is converted and resets to the first channel. In this mode all the channels are sampled and latched simultaneously until the reset to the first channel. This function is controlled by circuitry external to the A/D converter and required jumper modifications as specified by the manufacturer. 


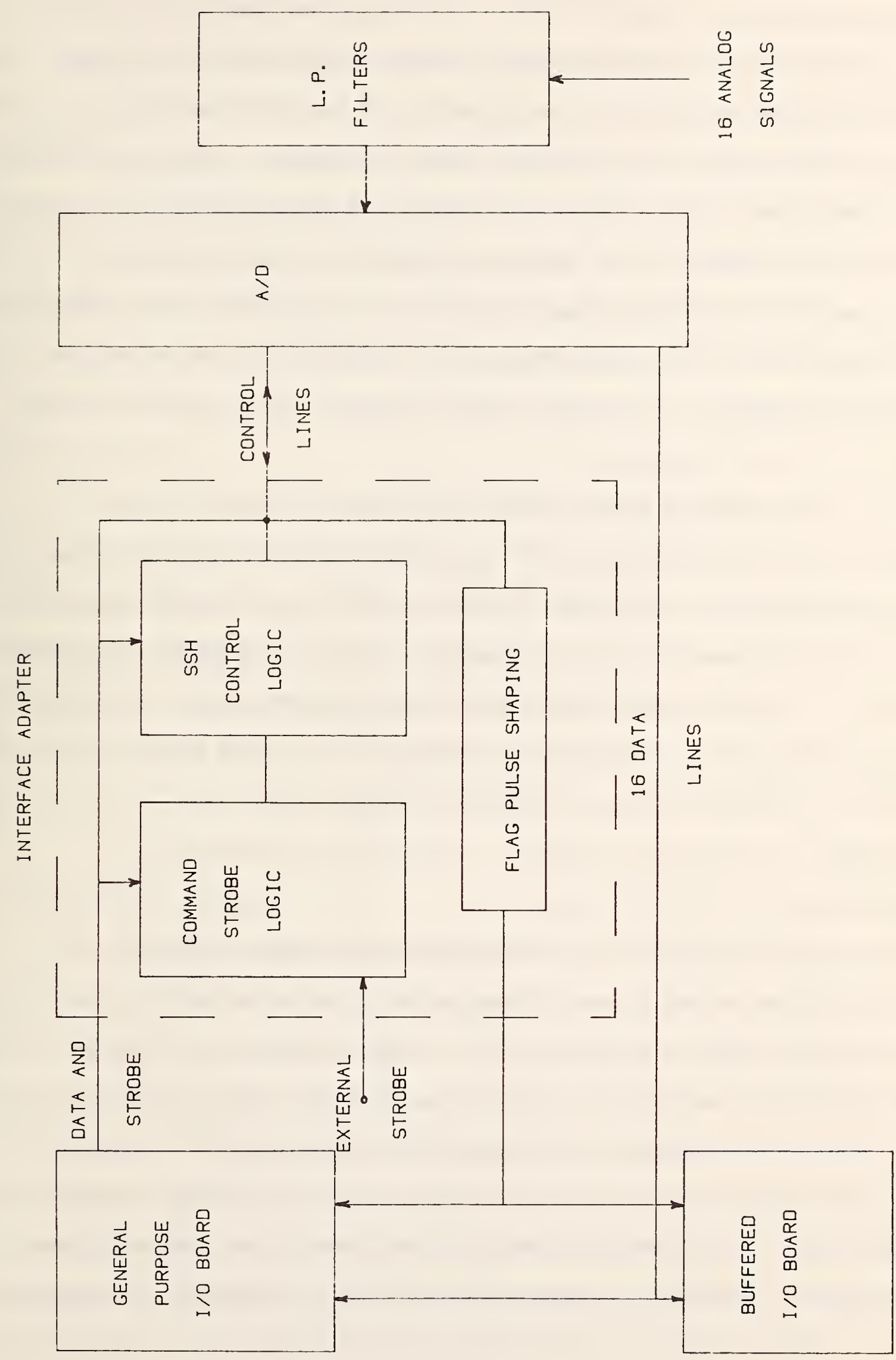


The strobe pulse activating the $A / D$ is externally selected from either a pulse generator or the interface card. In the sequential mode of operation it is important that the delay between initiation of holding by the simultaneous sample-and-hold modules and conversion of the signal be kept small to avoid errors due to sample-and-hold "droop" (leakage). Thus, especially at low conversion rates, a burst of rapid (e.g., 250,000 per second) strobes is desirable to convert all of the channels quickly. For this reason a pulse generator with countable burst capability is employed in the sequential mode of operation. The random address mode of operation may employ either the external strobe or the computer-supplied strobe, though the rate of the latter is not easily adjusted.

The sample-and-hold control logic ("SSH Control" in Fig. 2) was required because of the difference in operation between the sequential and random address modes. In sequential operation the signals are sampled and held at the first channel and not resampled until all the channels have been converted. Thus it is conveniently controlled by the Frame Sync line which is true only when the first channel is addressed. In random address mode, sampling is required before each addressed channel; thus a data line from the computer is utilized for control. In both cases the operation is synchronized by the strobe pulses.

The general purpose TTL interface card for the computer is used for controlling the function of the A/D subsystem, by using the output registers, and for reading small amounts (up to $32 \mathrm{~K}$ words) of data. This card and, indeed, the entire subsystem I/0, uses ground-true TTL logic. Jumpers are set on the card to produce a level change on the output strobe line which is reset when a flag strobe is received. The output data are always present on the data lines. The input data consist of the twelve actual data bits plus the Frame Sync indicator to detect possible errors in transmission sequencing. 
For high speed large sample data acquisition special DMA operations must be employed. This requires the use of a modified disc interface board available from the computer manufacturer. It contains a FIFO (first-in-first-out) memory to provide buffering required by head-movement latencies in the disc write operations. The interface is rather simple: the data lines, including the Frame Sync, and a strobe line are all that are required. The strobe pulse, however, must be properly shaped for satisfactory operation of the board. In particular the pulse duration must be close to $500 \mathrm{nsec}$. Thus a TTL monostable multivibrator ("one-shot") is inserted between the $A / D$ converter (which supplies a 1 usec pulse) and the interface board.

In order to prevent contamination of low frequency signals by frequencies higher than one-half the digitizing rate ("aliasing"), the incoming analog signals are filtered by sharp cutoff ( $80 \mathrm{db}$ per octave) IEEE-488 bus programmable filters. Each of the sixteen channels has an adjustable D.C. input offset matched to the signal levels. Gain, in addition to cut-off frequency, is programmable independently for each channel.

\section{Minicomputer System}

The minicomputer system selected to satisfy both the data acquisition requirements and that data reduction and analysis requirements outlined earlier includes 1.5 Mbytes of memory, a floating-point processor, a 50 Mbyte disc, a nine-track tape drive, a console, a printer, and a plotter (see Fig. 3). Three features in particular are of importance to the data acquisition and analysis functions of interest. First, the required highthroughput hardware and software are developed and proven for the application, requiring only integration into the overall system. In particular, a pair of system drivers are used without any modification to handle the data 


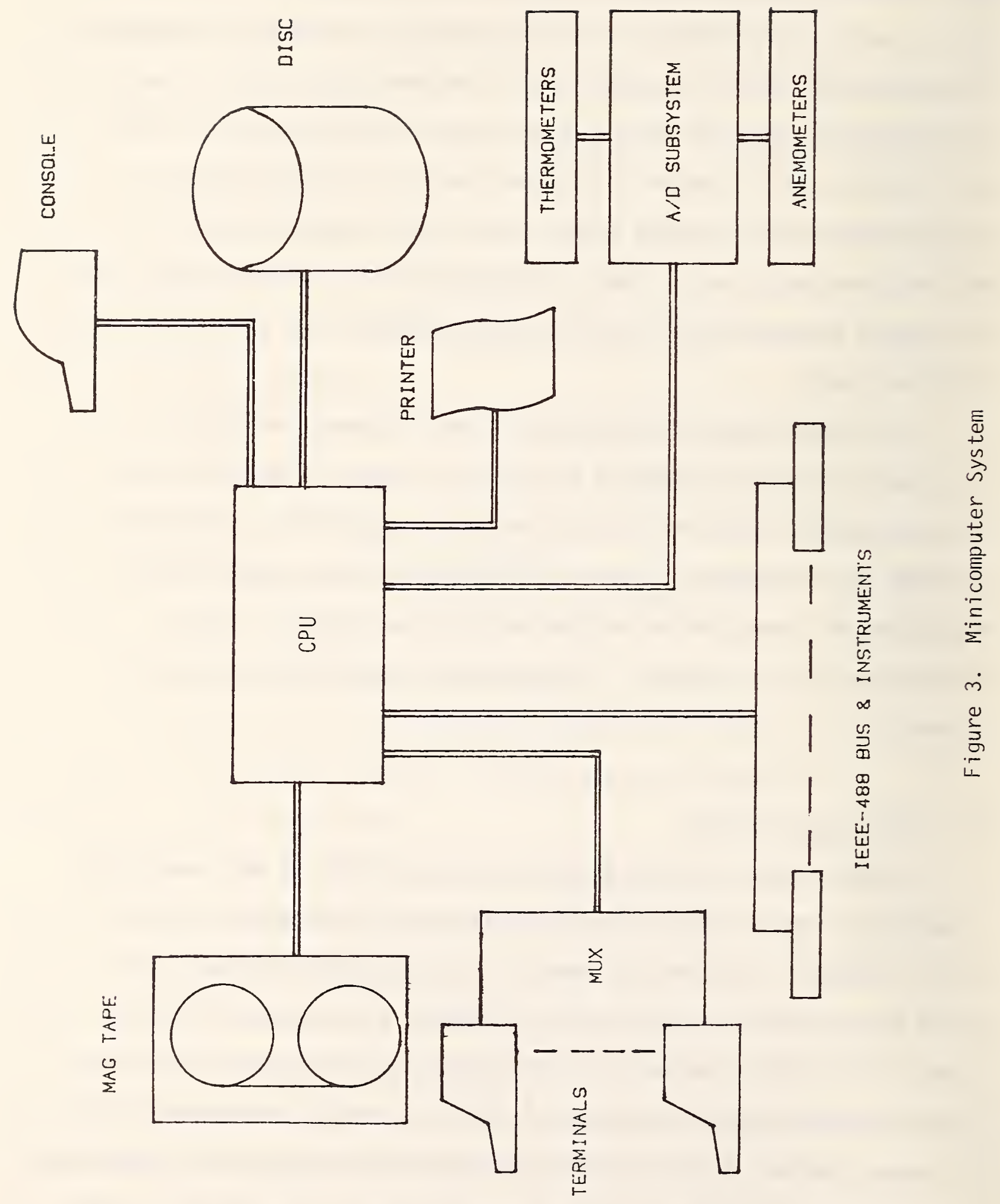


input and the disc writing. Second, the system can handle (both in hardware and in software) large arrays of data. This greatly reduces the time required for data analysis since large amounts of data are collected by the system. Third, the system has microcoded array-handling routines which increase the speed of such operations by an order of magnitude. Again, this is important because of the large arrays of data to be manipulated.

Flexibility and expandability of the system is met both in hardware (for instance in a reasonable number of $I / 0$ slots) and in the operating system (which has the capability for handling a number of users functions simultaneous ly). Fortran is the primary system language permitting use of the wide variety of scientific programs available. For example, a version of the NCAR (National Center for Atmospheric Research) graphics package has been installed on the system.

V. Velocity and Temperature Measurement Subsystems

A. Velocity Instrumentation

Since the first research project to be undertaken using the data aquisition system involved a flow well-suited to hot-wire anemometry, mixing in a co-flowing jet configuration, this technique of velocity measurement was selected for forming the multi-channel velocity subsystem. Each of the several techniques available for velocity measurement are more or less well-suited to a particular flow environment, and among the requirements for a straightforward application of hot-wire anemometry are ${ }^{14}$ : flow in predominantly one direction; negligible temperature changes (unless compensation is used); and a single-phase medium (gas) to prevent wire breakage. Among the major advantages of hot-wire anemometry for use in appropriate flows are ${ }^{15}$ : high frequency response; good spatial resolution; no need for particles as in laser velocimetry; simplicity of construction and operation; and low cost. The latter is especially 
important when an array of sensors is required.

of the two major types of hot-wire anemometry, constant-temperature and constant-current, the former has gained predominance because of its simplicity. The development of small, rugged, and relatively inexpensive commercial units such as those used in this facility has made practical the multi-probe approach to velocity measurement necessary for contemporary research. The constant-temperature anemometer ${ }^{16}$ is essentially a servo-loop using a high-gain amplifier to supply a current through the probe's wire for maintaining a nominally constant temperature (resistance) (Figure 4). Careful selection of components is required, however, to assure low noise, stability, sensitivity to velocity, insensitivity to temperature, and over-current protection of the hot-wire.

The specific units employed in this facility were mounted in boxes with probe and output connectors, power switches, and battery terminals (for low-noise power). In addition, external connectors were incorporated for the control resistor, since its selection determines many of the above mentioned performance characteristics. The control resistor is typically adjusted to provide a resistance of the hot-wire between 1.5 and 2.0 times that of the wire with negligible current flowing.

The specific anemometers used here were specified to operate with a Pt wire $2.5 \mu \mathrm{m}$ in diameter and $1.0 \mathrm{~mm}$ in length. They are presently used successfully with wires down to $0.5 \mathrm{~mm}$ in length. For the purpose of forming various arrays of these probes as required by particular measurements, a new type of probe was designed to provide this desired flexibility. The probe (Figure 5) consists of a central stem of $1 / 32$ inch $(0.794 \mathrm{~mm})$ dri11 rod and two No. 80 jewelers broach tips approximately $0.33 \mathrm{~mm}$ tapering to $0.076 \mathrm{~mm}$ at the tip. Paper is used as insulation, and the parts are cemented with cyanoacrylate ester ("super") glue. Number 30 wire-wrapping wire is 


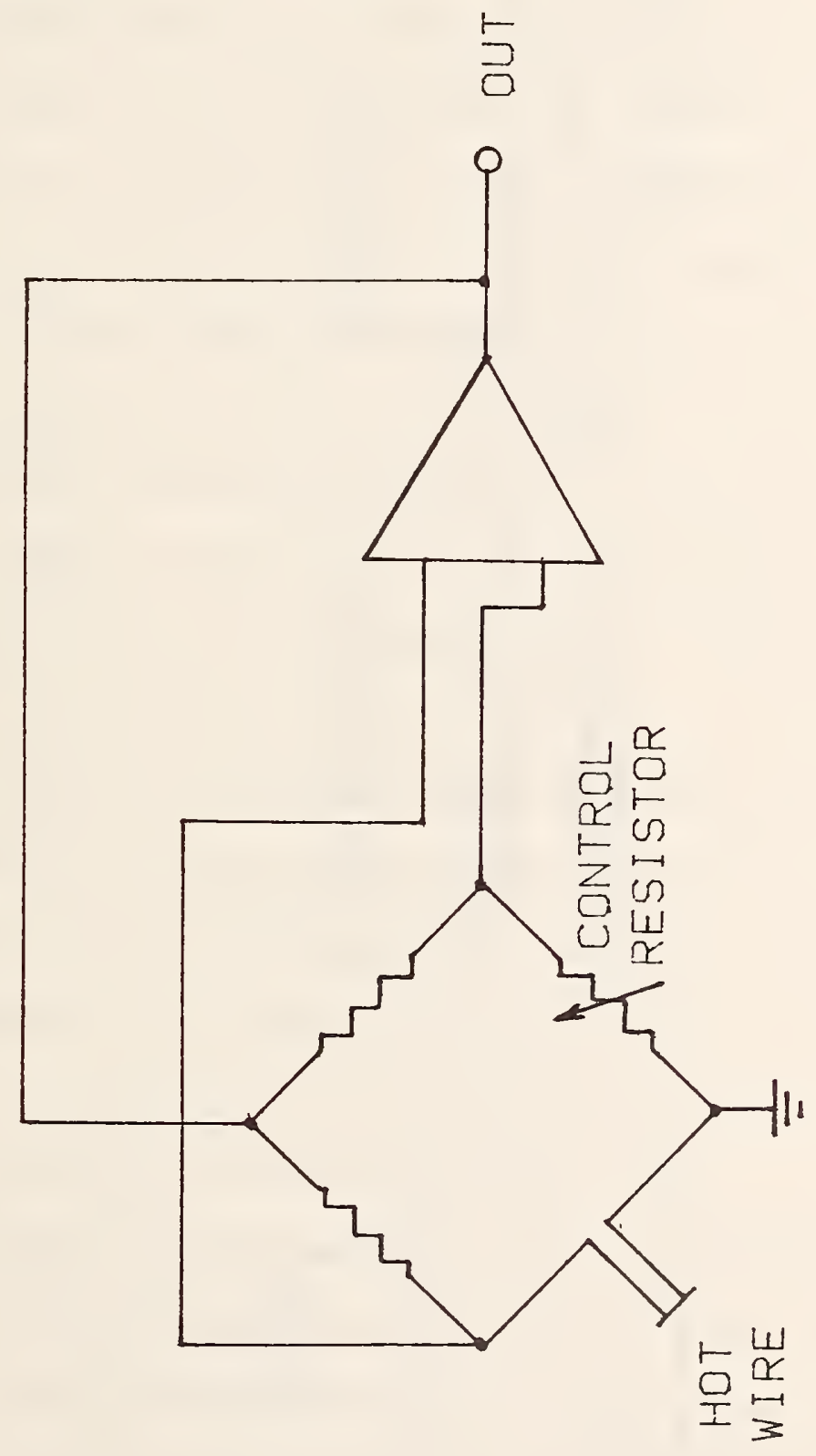

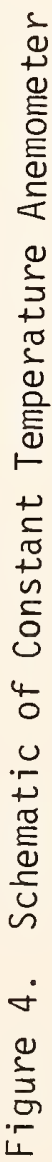




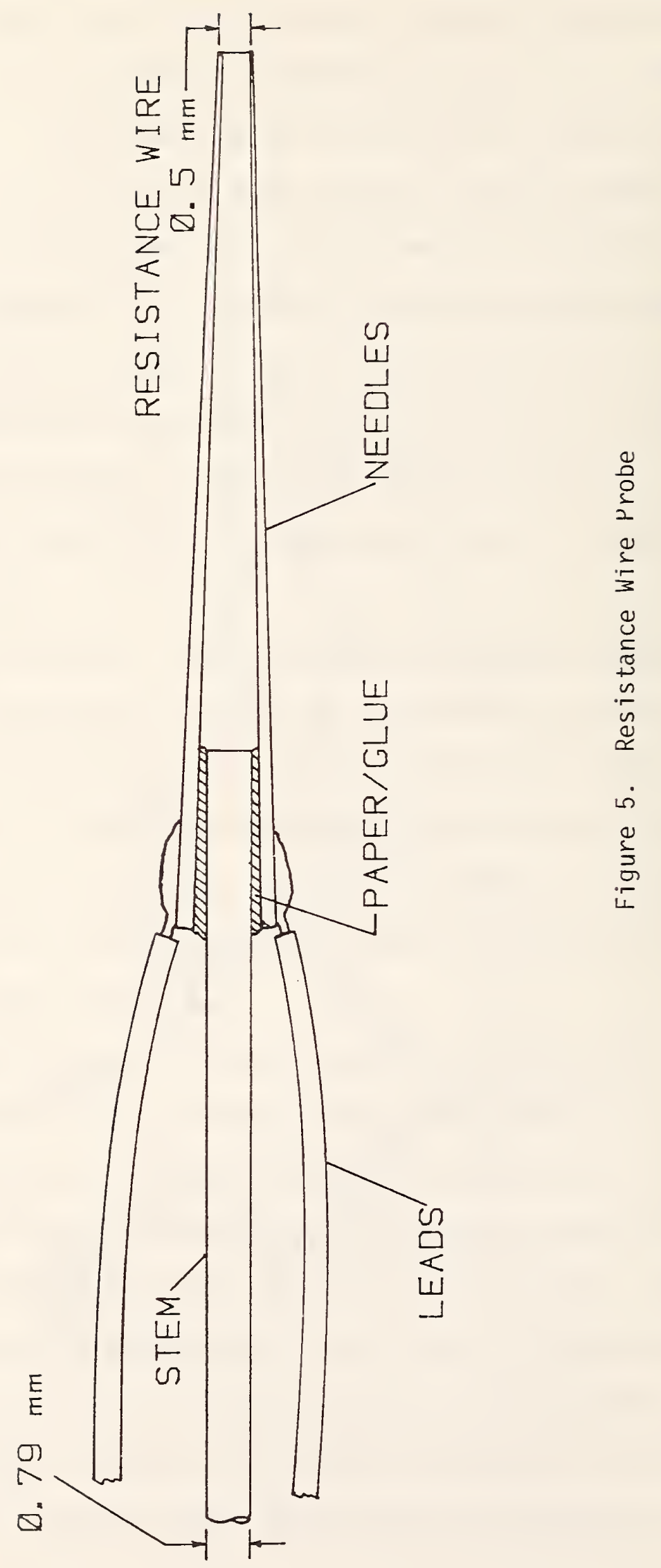


then soldered on the broach bases for electrical leads. The stems then permit mounting in a variety of arrangements. No commercially available probes were satisfactory for the desired measurements.

\section{B. Temperature Instrumentation}

The flow from the co-flowing jet apparatus may be heated from zero to twenty degrees Celsius above ambient for purposes of "marking" the jet fluid. Temperature or temperature-and-velocity combined may then be measured as required. This modest range of temperature together with the same requirements as for the velocity measurements in terms of spatial resolution, frequency response, and sensitivity suggest the use of resistance wire ("cold-wire") temperature measurements. ${ }^{17}$ This method uses a constant current source to measure the resistance (temperature sensitive) of a fine wire. The current is kept very low to minimize heating of the wire so that the wire signal is insensitive to velocity fluctuations. No commercial sources of such instruments are known (meeting the stated requirements), but the circuits are easily constructed.

The particular resistance-wire instruments used in this system are shown schematically in Figure 6 . A current of nominally $0.1 \mathrm{ma}$ is supplied to a Pt wire $1.25 \mu \mathrm{m}$ by $0.5 \mathrm{~mm}$. The voltage across the wire is then $D C$ amplified and sent to the anti-aliasing filters.

The probes used for the temperature measurements are the same as those used for velocity measurement except for the use of smaller diameter wire for improving frequency response. If velocity and temperature were to be measured simultaneously, both wires would need to be present either in an x-pattern or parallel. 


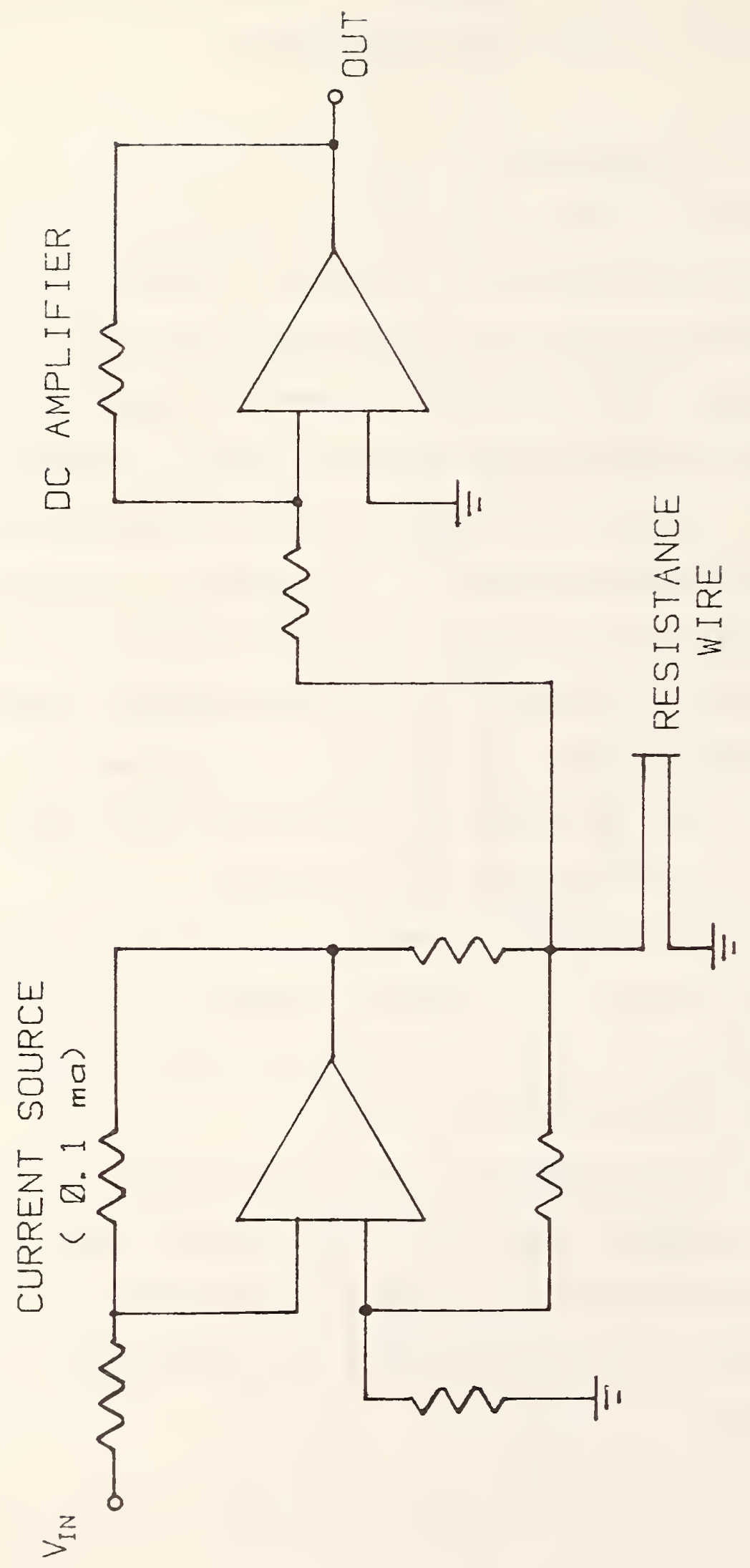

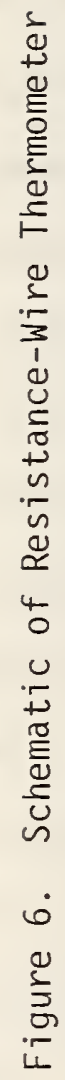


VI. System Operation and Performance

A. Velocity Calibration

Since the Low Velocity Airflow Facility is a low-velocity calibration facility as well as a research facility, a calibration system for the velocity probes is in place. For very low velocities (below about $1 \mathrm{~m} / \mathrm{sec}$ ) a laser velocimeter system may be used. For higher velocities a Pitot-tube system is more easily utilized. In either case the velocity probes are placed in the freestream and the velocity varied while measuring the anemometer voltages. The data acquisition system is used to measure an average voltage from the anemometers, thus calibrating the entire system including filters and $A / D$ converter.

The Pitot-tube system, including the Pitot-tube, a pressure transducer, and an IEEE-488 Bus digital voltmeter (as well as a slope gauge for calibration of the pressure transducer, as needed), is also connected to the computer system by the IEEE-488 bus. Thus the anemometer calibration may be performed programmatically with assistance of the operator for setting air velocity and pressure transducer range.

The data acquired by the computer is fit by a least squares routine to the function $^{18}$

$$
U=\left(A+B E+C E^{2}+D E^{3}\right)^{2}
$$

where $U$ is the velocity and $E$ the voltage. A typical calibration is shown in Figure 7. The calibration data is stored in a disc file for use in data reduction and for future reference.

\section{B. Temperature Calibration}

To "mark" the air emitted by the jet in the wind tunnel the air is heated slightly by a resistance heater mounted just upstream of the flow conditioning devices near the exit of the jet. This heater is also used to calibrate the 


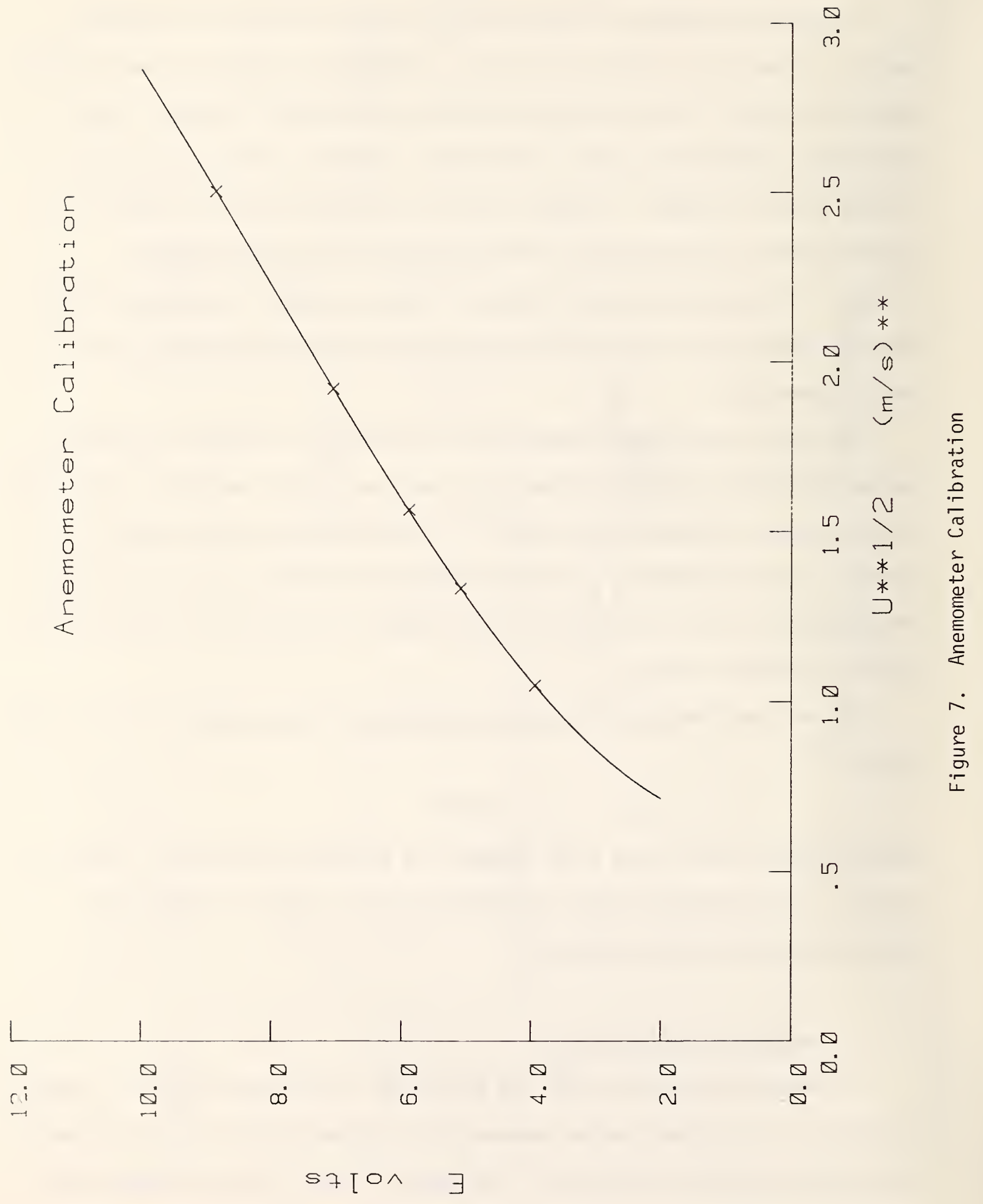


resistance-wire thermometers by varying the temperature of the air from the jet and measuring the voltage from the thermometers when placed in the heated stream. The temperature of the stream is monitored by a thermistor mounted in the flow conditioning section of the jet. Since the range of temperature is small (about $20^{\circ} \mathrm{C}$ ), a linear least squares curve is fit to the data:

$$
\sigma=A^{\prime}+B^{\prime} \cdot E
$$

where $\sigma$ is the temperature and $E$ the voltage measured as for the velocity calibrations. A typical calibration is shown in Figure 8 . This calibration data is also stored in a disc file for later use.

\section{Data Acquisition}

Data may be acquired by the computer system in several ways depending on the function to be performed. Small amounts of data (typically less than several thousand) may be transferred via DMA to a data array in a normally addressed region (not requiring extended addressing). The previously mentioned calibration routines operate in this manner since data is acquired from only one probe at a time and at a fairly slow rate (typically 1000 per second).

Other applications requiring only one or a few probes and a small amount of data, but more than the several thousand as before, such as for frequency spectra on one probe, may use DMA to an extended data array (1imited to about 26000 data). An example of such a data acquisition is shown in Figure 9, a velocity spectrum in the linear growth region of the shear layer. The spectrum is computed as an overlapping average ${ }^{19}$ of segments of data 1024 in length for a total of 16384 data.

A second example of using the DMA to an extended data array is shown in Figure 10, a sample of data from an array of temperature probes placed in the early region of the jet flow (but downstream of the linear growth region). 


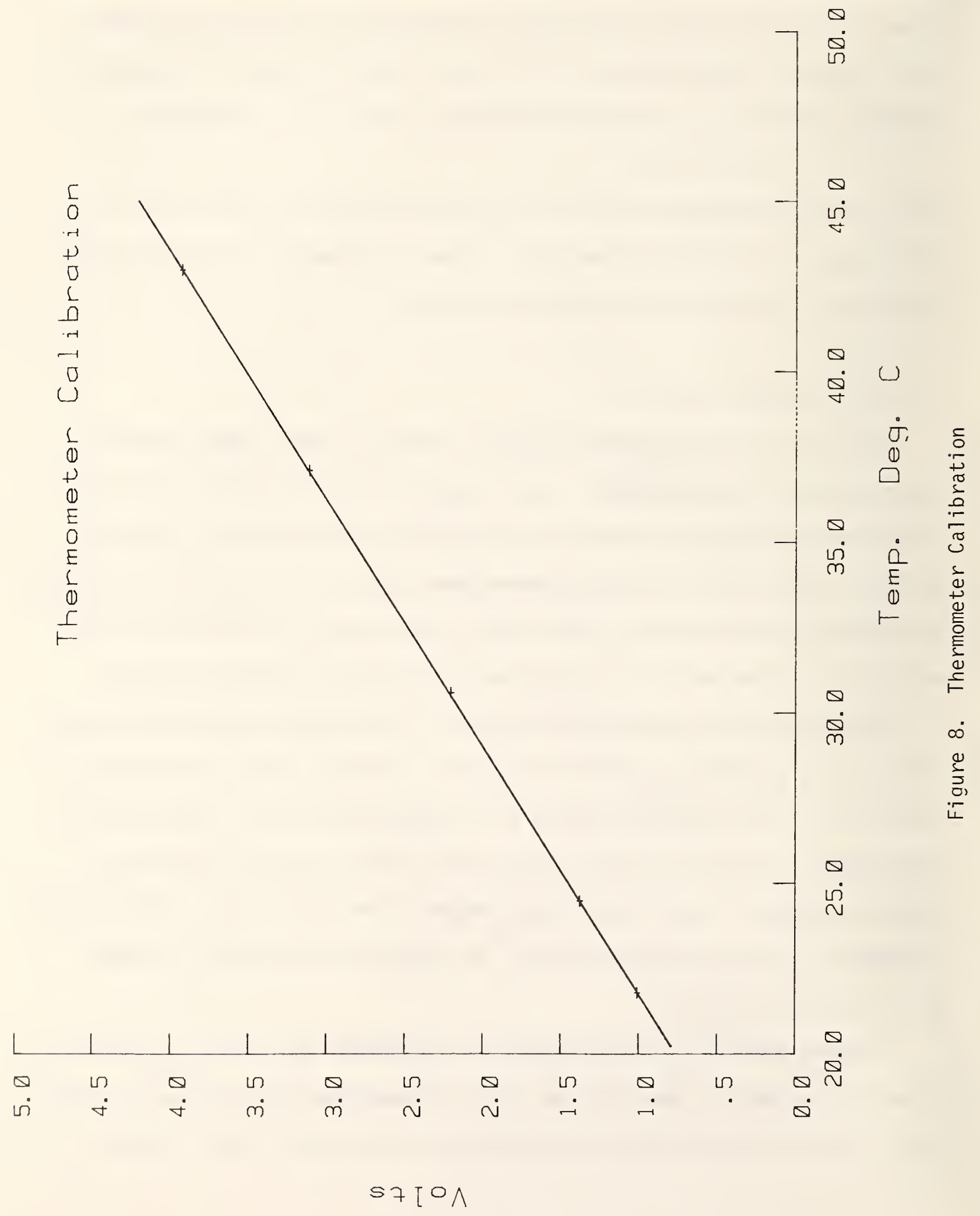




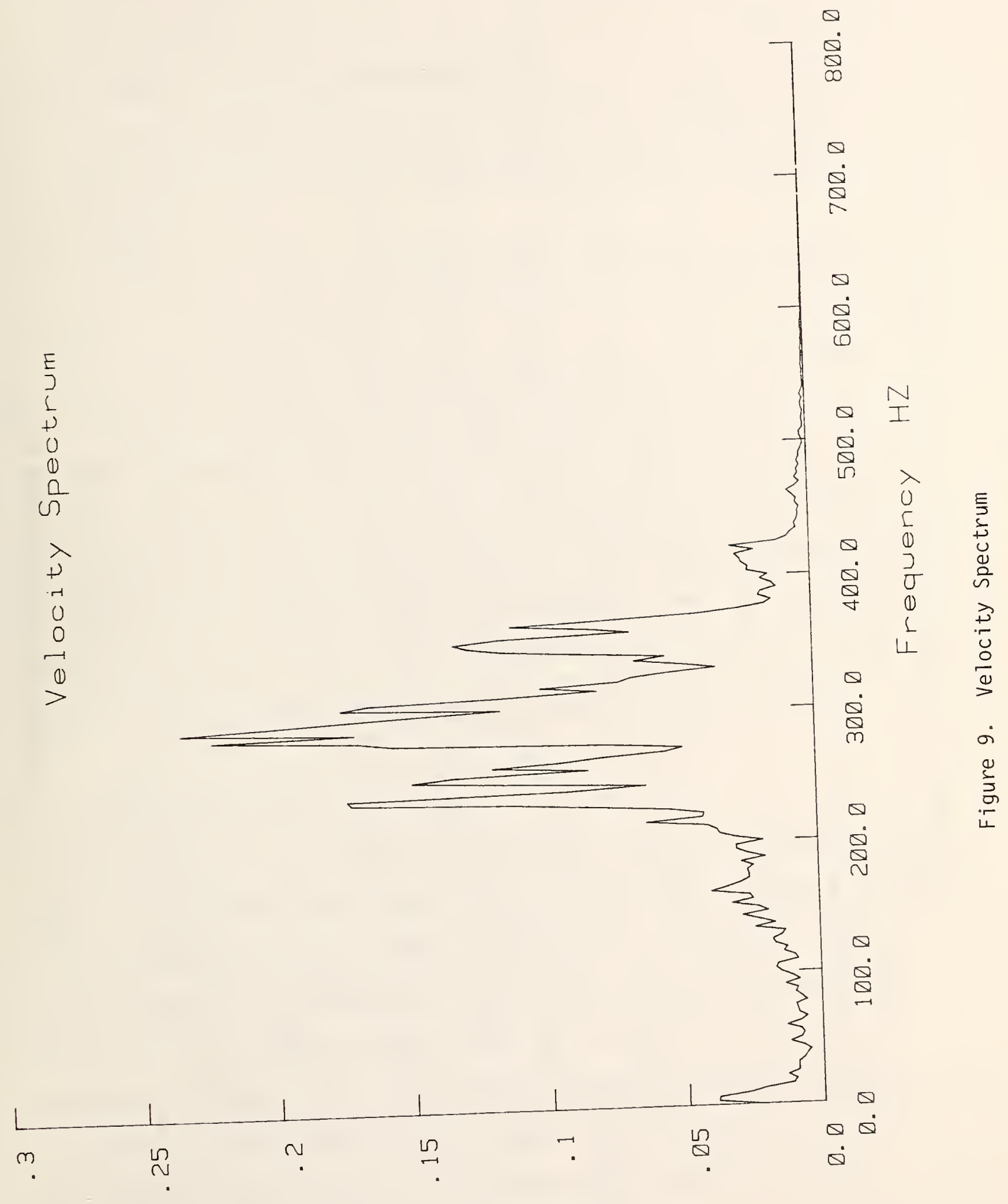




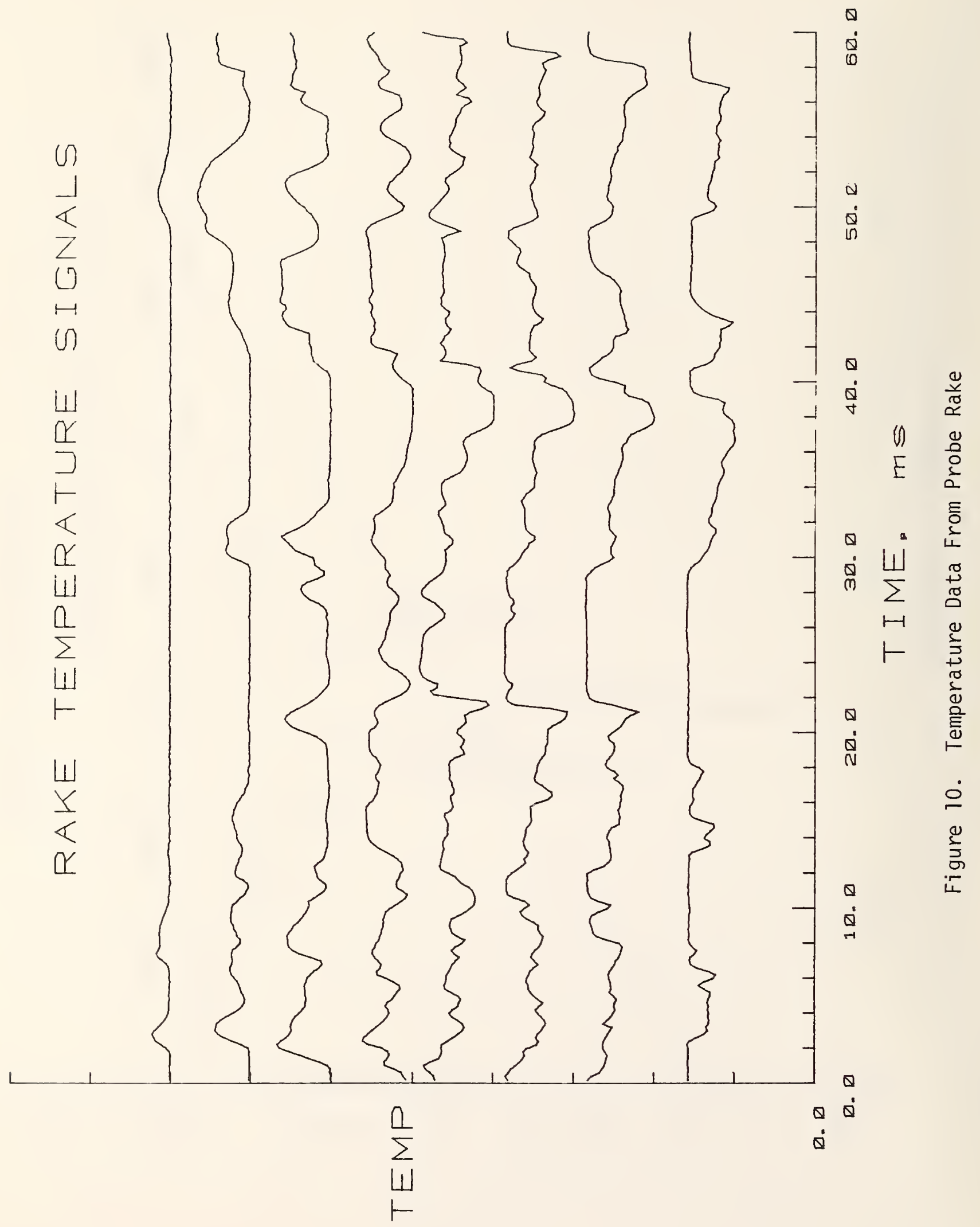


Here, vortices have developed wrapping up and entraining the outer, cooler air and forming temperature fronts on the leading edges of the vortices. In addition to "marking" the vortices, these fronts also serve to demonstrate the good response of the resistance-wire probes to a temperature change. In the figure the response rises to $63 \%$ of the change in temperature in approximately $0.4 \mathrm{~ms}$ from which a response of at least $2.5 \mathrm{KHz}$ may be estimated.

The above data acquisition methods require only access to a DMA channel for operation. Two such channels are in the system and only one is normally in use (by the disc) unless the magnetic tape transport is in operation. Thus data acquisition depends almost solely on program run priority. The high speed throughput method, however, needs sole access to the disc, thus requiring that the multi-user capability of the system be suspended during its operation. This difficulty makes the use of the high-throughput method a last choice. It is, however, absolutely necessary for most data acquisition from an array of probes for any normal duration of run, especially if the internal structure of the large scale motions or vortices is desired.

\section{Further Applications}

Application of this system is of course not limited to the measurements of velocity and temperature discussed above. The system is flexible enough in terms of input signal requirements to process one or multiple signals from measurements of concentration, shear stress, light extinction, light scattering, etc., provided the data rates can be handled. Even some of the software developed for the velocity and temperature measurements may be applicable to these other types of signals, as for instance in multiphase flow where agglomerations of one phase may be examined like the large-scale motions in the preceding discussions. 
Another area of application for which this minicomputer system and its real-time structure is well-suited is that of active control. The natural step beyond data acquisition of large-scale motions, for example, is the alteration of their properties by manipulating some flow parameter in an attempt to optimize a desired feature, such as mixedness. Such control requires the high speed data acquisition and real-time capabilities that this system provides.

\section{References}

1. Richards, B. E., Introduction to Measurement of Unsteady Flows, in Measurement of Unsteady Fluid Dynamic Phenomena, Hemisphere Publ., Washington, 1977, p. 5.

2. Tennekes, H., The Atmospheric Boundary Layer, Phys. Today, Jan. 1974.

3. Liepmann, H. W., The Rise and Fall of Ideas in Turbulence, American Scientist, vol. 67, March 1979.

4. Tennekes, H., and Lumley, J., A First Course in Turbulence, The MIT Press, Cambridge, MA, 1972, p. 28.

5. Laufer, J., New Trends in Experimental Turbulence Research, Annual Review of Fluid Mechanics, vol. 7, 1975, p. 307.

6. Cantwe11, B. J., Organized Motion in Turbulent Flow, Annual Review of Fluid Mechanics, vol. 13, 1981, p. 457.

7. Broadwe17, J. E., and Breidenthal, R. E., A Simple Model of Mixing and Chemical Reaction in a Turbulent Shear Layer, J. Fluid Mech., vol. 125, 1982 , p. 397.

8. Blackwelder, R. F., and Kaplan, R. E., On the Wall Structure of the Turbulent Boundary Layer, J. Fluid Mech., vol. 76, 1976, p. 89.

9. Subramanian, C. S., et al., Comparison of Conditional Sampling and Averaging Techniques in a Turbulent Boundary Layer, J. Fluid Mech. vol. 123,1982, p. 335 . 
10. Wallace, J. M., Brodkey, R. S., and Eckelmann, H., Pattern-recognized Structures in Bounded Turbulent Shear Flows, J. Fluid Mech. vol. 83, 1977, p. 673.

11. Corke, T., and Nagib, H., Discrimination of Coherent Features in Regular and Manipulated Turbulent Boundary Layers, Drag Reduction Symposium, 1982.

12.. Frenkiel, F. N., and Klebanoff, P. S., Statistical Properties of Velocity Derivatives in a Turbulent Field, J. Fluid Mech., vol. 48, 1971 , p. 183.

13. Purte11, L. P., and Klebanoff, P. S., A Low Velocity Airflow Calibration and Research Facility, MBS Tech. Note No. 989, 1979.

14. Hinze, J. 0., Turbulence, 2nd Ed., McGraw-Hi11, NY, 1975, pp. 83-134.

15. Comte-Bellot, G., Hot-wire and Hot-film Anemometers, in Measurement of Unsteady Fluid Dynamics Phenomena, B. E. Richards, ed., McGrawHi11, NY, 1977, pp. 123-162.

16. Blackwelder, R. F., Hot-wire and Hot-film Anemometers, in Methods of Experimental Physics, V.18, Part A, R. J. Emrich, ed., Academic Press, NY, 1981, pp. 259-315.

17. Hinze, J. 0., op. cit., pp. 135-139.

18. Drubka, R. E., and Wlezien, R. W., Efficient Velocity Calibration and Yaw-Relation Truncation Errors in Hot-wire Measurements of Turbulence, Bulletin of the American Physical Society, vol. 24, no. 8, October 1979.

19. Programs for Digital Signal Processing, W. R. Crone, ed., IEEE Press, NY, 1979. 
NBS-114A (REV. 2-8C)

U.S. DEPT. OF COMM.

BIBLIOGRAPHIC DATA

SHEET (See instructions)

4. TITLE AND SUBTITLE
1. PUBLICATION OR REPORT NO.

NBS TN 1181
2. Performing Organ. Report No.

3. Publication Date

November 1983

\section{A High-Speed Data Acquisition System for Eluid Mechanics Measurements}

5. AUTHOR(S)

L. P. Purte 11

6. PERFORMING ORGANIZATION (If joint or other than NBS, see instructions)

7. Contract/Grant No.

NATIONAL BUREAU OF STANDARDS

DEPARTMENT OF COMMERCE

WASHINGTON, D.C. 20234

8. Type of Report \& Period Covered

Final

9. SPONSORING ORGANIZATION NAME AND COMPLETE ADDRESS (Street, City. Stote, ZIP)

Same as in item 6 above.

10. SUPPLEMENTARY NOTES

Document describes a computer program; SF-185, FIPS Software Summary, is attached.

11. ABSTRACT (A 200-word or less factual summary of most significant information. If document includes a significant bibliography or literature survey. mention it here)

The requirements, characteristics, and performance of a minicomputer-based data acquisition and analysis system suitable for research in fluid mechanics processes are presented. The particularly stringent requirements imposed by unsteady and turbulent flows are discussed including estimates of the required data acquisition rates and durations.

12. KEY WORDS (Six to twelve entries; alphabetical order: capitalize only proper names; and separate key words by semicolons) data acquisition; fluid mechanics; hot-wire anemometry; measurement; minicomputers; turbulence.

13. AVAILABILITY

苏 Unlimited

$\square$ For Official Distribution. Do Not Release to NTIS

[X] Order From Superintendent of Documents, U.S. Government Printing Office, Washington, D.C. 20402.

14. NO. OF PRINTED PAGES

31

15. Price

Order From National Technical Information Service (NTIS), Springfield, VA. 2216I 


\section{NBS TECHNICAL PUBLICATIONS}

\section{PERIODICALS}

JOURNAL OF RESEARCH-The Journal of Research of the National Bureau of Standards reports NBS research and develop. ment in those disciplines of the physical and engineering sciences in which the Bureau is active. These include physics, chemistry, engineering, mathematics, and computer sciences. Papers cover a broad range of subjects, with major emphasis on measurement methodology and the basic technology underlying standardization. Also included from time to time are survey articles on topics closely related to the Bureau's technical and scientific programs. As a special service to subscribers each issue contains complete citations to all recent Bureau publications in both NBS and nonNBS media. Issued six times a year. Annual subscription: domestic $\$ 18$; foreign $\$ 22.50$. Single copy, $\$ 5.50$ domestic; $\$ 6.90$ foreign.

\section{NONPERIODICALS}

Monographs-Major contributions to the technical literature on various subjects related to the Bureau's scientific and technical activities.

Handbooks-Recommended codes of engineering and industrial practice (including safety codes) developed in couperation with interested industries, professional organizations, and regulatory bodies.

Special Publications-Include proceedings of conferences spon. sored by NBS, NBS annual reports, and other special publications appropriate to this grouping such as wall charts, pocket cards, and bibliographies.

Applied Mathematics Series-Mathematical tables, manuals, and studies of special interest to physicists, engineers, chemists, biologists, mathematicians, computer programmers, and others engaged in scientific and technical work.

National Standard Reference Data Series-Provides quantitative data on the physical and chemical properties of materials, compiled from the world's literature and critically evaluated Developed under a worldwide program coordinated by NBS under the authority of the National Standard Data Act (Public Law 90-396).

NOTE: The principal publication outlet for the foregoing data is the Journal of Physical and Chemical Reference Data (JPCRD) published quarterly for NBS by the American Chemical Society (ACS) and the American Institute of Physics (AIP). Subscriptions, reprints, and supplements available from ACS, 1155 Sixteenth St., NW, Washington, DC 20056
Building Science Series-Disseminates technical in?ormation developed at the Bureau on building materials, components, systems, and whole structures. The series presents research results, test methods, and performance criteria related to the structural and environmental functions and the durability and safety characteristics of building elements and systems.

Technical Notes-Studies or reports which are complete in themselves but restrictive in their treatment of a subject. A nalogous to monographs but not so comprehensive in scope or definitive in treatment of the subject area. Often serve as a vehicle for final reports of work performed at NBS under the sponsorship of other government agencies.

Voluntary Product Standards-Developed under procedures published by the Department of Commerce in Part 10. Title 15, of the Code of Federal Regulations. The standards establish nationally recognized requirements for products, and provide all concerned interests with a basis for common understanding of the characteristics of the products. NBS administers this program as a supplement to the activities of the private sector standardizing organizations.

Consumer Information Series-Practical information, based on NBS research and experience, covering areas of interest to the consumer. Easily understandable language and illustrations provide useful background knowledge for shopping in today's technological marketplace.

Order the above NBS publications from: Superintendent of Docunients. Government Printing Office, Washington. DC 20402.

Order the following NBS publications-FIPS and NBSIR's-from the National Technical. Information Service. Springfield. VA 22161.

Federal Information Processing Standards Publications (FIPS PUB)-Publications in this series collectively constitute the Federal Information Processing Standards Register. The Register serves as the official source of information in the Federal Government regarding standards issued by NBS pursuant to the Federal Property and Administrative Services Act of 1949 as amended. Public Law 89-306 (79 Stat. 1127), and as implemented by Executive Order 11717 (38 FR 12315, dated May 11, 1973) and Part 6 of Title 15 CFR (Code of Federal Regulations).

NBS Interagency Reports (NBSIR) - A special series of interim or final reports on work performed by NBS for outside sponsors (both government and non-government). In general, initial distribution is handled by the sponsor: public distribution is by the National Technical Information Service, Springfield, VA 22161. in paper copy or microfiche form 
U.S. Department of Commerce

National Bureau of Standards

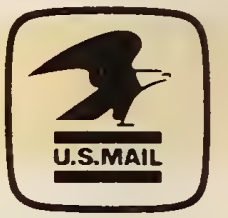

Washington, D.C. 20234

Official Business

Penalty for Private Use $\$ 300$

POSTAGE AND FEES PAID U.S DEPARTMENT OF COMMERC COM-215

FIRST CLASS 